\title{
Images
}

\section{The floating foot: a case of total talar dislocation}

\author{
Ariel Hendin, MD*; Hans Rosenberg, MD*
}

A 36-year-old male was brought by ambulance to the emergency department after he lost control of his motorcycle and crashed into a tree. He was helmeted and wearing body armor at the time. On primary and secondary survey, he had no apparent injuries, except a grossly deformed left ankle. There were no signs of an open injury, but there was skin tenting over the left lateral ankle. Pulses could not be palpated in the left foot, but a dorsalis pedis pulse was detectable with Doppler. The patient had intact sensation and could move his toes.

A portable X-ray was obtained, which demonstrated a complete dorsal dislocation of the talus (Figures 1 and 2).

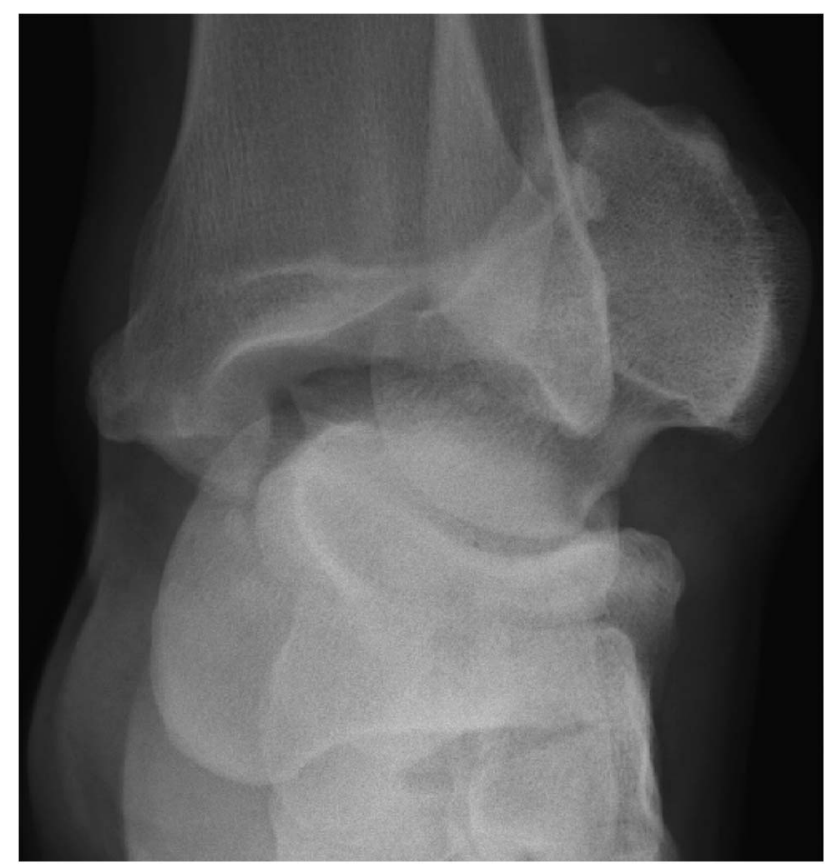

Figure 1. AP ankle X-ray demonstrates medial dislocation of the talus.
With procedural sedation and the assistance of the orthopaedics team, the talus was urgently reduced with traction on the hindfoot and countertraction on the distal tibia. The ankle was immobilized in a posterior splint and the patient was admitted to the hospital for further workup. A CT scan of the ankle demonstrated fracture fragments from the posterior process of the talus in the tibiotalar joint space, for which he underwent arthroscopic debridement a few days later.

Although the talus is the only bone in the body with no tendon or muscle attachments, dislocation is uncommon due to its strong ligamentous attachments and exacting bony articulations. ${ }^{1}$ Complete dislocation,

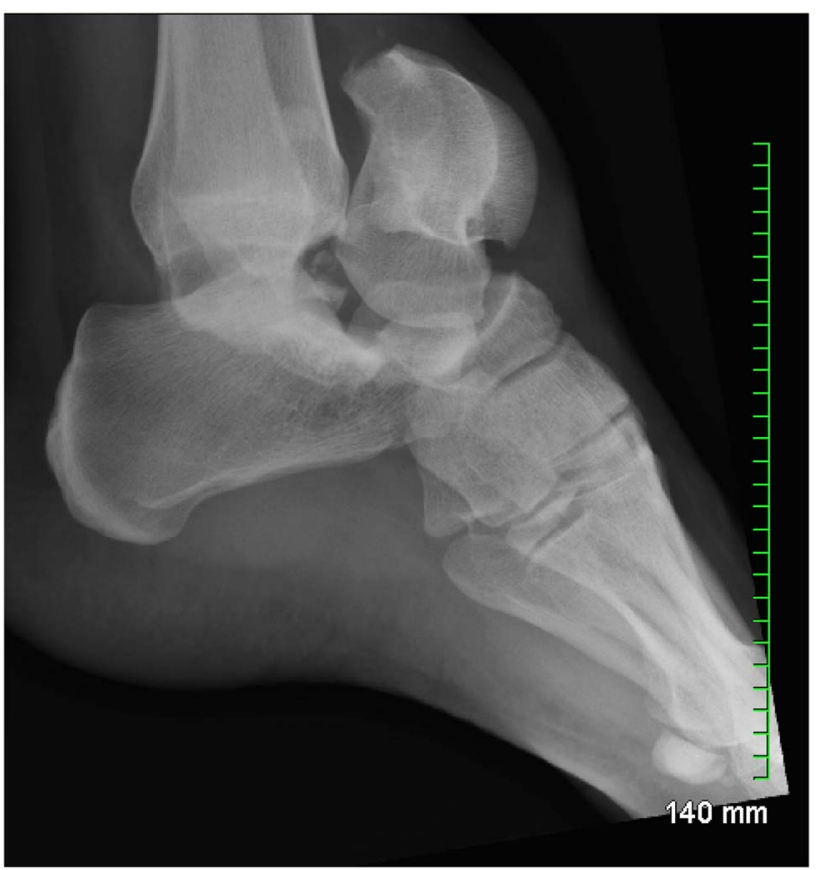

Figure 2. Lateral ankle X-ray demonstrates dorsal dislocation of the talus with fracture of the posterior talar process.

From the *Department of Emergency Medicine, University of Ottawa, Ottawa, ON.

Correspondence to: Dr. Ariel Hendin, The Ottawa Hospital, 1053 Carling Avenue, E-Main Room EM-206, Box 227, Ottawa, ON K1Y 4E9; Email: ahendin@toh.on.ca. 
which involves disarticulation from the tibiotalar, talonavicular, and subtalar joints, is due to high-energy forced supination or pronation at the ankle and is often an open injury; closed dislocations as seen in this case are extremely rare. ${ }^{2}$ Reduction of the talus usually requires an open technique, although in case reports closed reduction where possible is associated with more favourable outcomes. ${ }^{1,3,4}$

Keywords: Orthopaedics, ankle, dislocation

Competing interests: None declared.

\section{REFERENCES}

1. Johnson B, Rouholamin N, Patel A. Total dislocation of the talus. Eur 7 Orthop Surg Traumatol 2011;22(8): 633-7.

2. Sharifi SR, Ebrahimzadeh MH, Ahmadzadeh-Chabok H, et al. Closed total talus dislocation without fracture: a case report. Cases 7 2009;2:9132.

3. Papnikolaou A, Siakantaris P, Maris J, et al. Successful treatment of total talar dislocation with closed reduction: a case report. Foot Ankle Surg 2002;8(4):245-8.

4. Rhanim A, Zanati RE, Ouchrif Y, et al. Nonoperative treatment of closed total talus dislocation without fracture: a case report and literature review. 7 Clin Orthop Trauma 2014;5(3):172-5. 